\title{
A Survey Study of the Use of Nutritional Supplements in Taiwan Elite Athletes 台灣優秀運動員使用營養增補劑之調查研究
}

\author{
Zong-Yan $\mathrm{CAI}^{1}$ Ku-Fu HSU ${ }^{2}$ Yi-An LIN $^{3}$ \\ Cheng-Chen HSU $^{4}$ Yu-Wa TSENG \\ Borcherng $\mathrm{SU}^{6} \quad$ Mei-Chich $\mathrm{HSU}^{7}$
}

${ }^{I}$ General Education Center, Tuz Chi College of Technology, Hualien, TAIWAN

${ }^{2}$ Graduate Institute of Physical Education, National Sports University, Taoyuan County, TAIWAN

${ }^{3}$ Graduate Institute of Coaching Science, National Sports University, Taoyuan County, TAIWAN

${ }^{4}$ School of Medicine, Taipei Medical University, Taipei, Taiwan.

${ }^{5}$ Department of Physical education and Health, Taipei Physical Education College Taipei, TAIWAN

${ }^{6}$ Department of Pathology, Buddhist Tzu Chi General Hospital, Hualien, TAIWAN

${ }^{7}$ Graduate Institute of Sports Science, National Sports University, Taoyuan County, TAIWAN

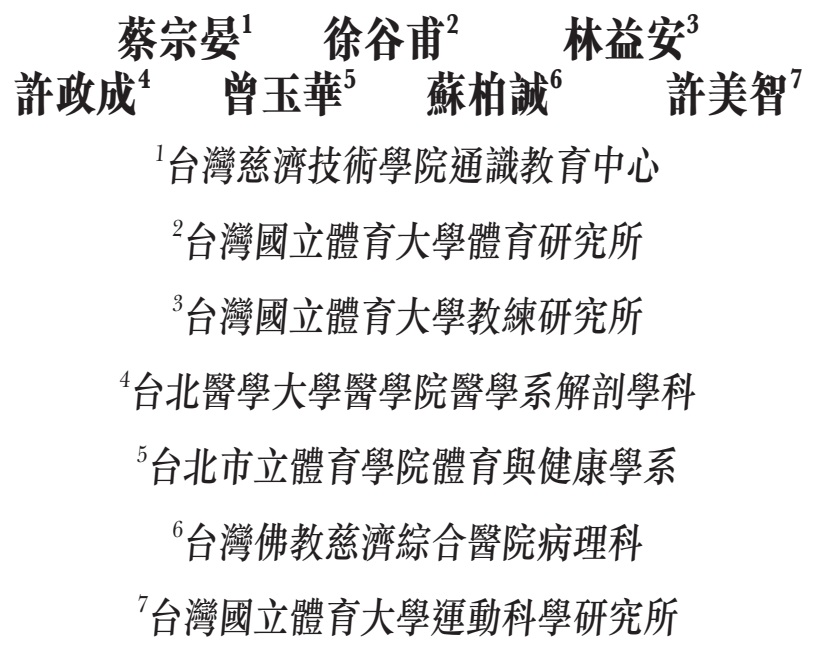

대

\begin{abstract}
The purpose of this study was to understand the current usage of nutritional supplements in Taiwan elite athletes. This study adopting purposive sampling, we surveyed 105 male and 80 female athletes across sports selected for doping control at the National Athletic Games during year 2007 in Taiwan to understand the athletes' use of nutritional supplements 14 days prior to the games. Categories of nutritional supplements include vitamin/mineral supplements, amino acid supplements, instant energy supplements, healthcare foods, and drinks. The results indicated $88.1 \%$ of the athletes have used nutritional supplements. The usage rates for different categories of nutritional supplements were vitamin/mineral supplements (48.1\%),
\end{abstract}


drinks (45.9\%), healthcare foods (39.5\%), amino acid supplements (31.9\%), and instant energy supplements (24.9\%). Female athletes had a higher tendency to use vitamin/mineral supplements (55.0\% vs. $42.9 \%)$ and healthcare foods (47.5\% vs. $33.3 \%)$ compared to male athletes. Among the sports, weightlifters/bodybuilders and swimmers have all used nutritional supplements (100\%), especially the use of creatine for the weightlifters/bodybuilders (69.7\%) and multivitamin (76.2\%) for the swimmers. In addition, the most consumed types in different categories of nutritional supplements were multivitamins (37.3\%) for vitamin/ mineral supplements, creatine (26.5\%) for amino acid supplements, chocolate (15.1\%) for instant energy supplements, Cordymax Cs-4 Capsules (16.2\%) for healthcare foods, and sports drinks (42.4\%) for drinks. In conclusion, the results on the current use of nutritional supplements for Taiwan elite athletes could act as a reference to coaches, athletes and sports organizations.

Keywords: National Athletic Games, exercise, supplementation

\section{摘要}

本研究目的在於了解台灣優秀選手使用營養增補劑的現沉。本研究採立意抽樣, 我們調查了2007年全國運動會 (全運會) 期間, 105 名男性以及 80 名女性需接受運動禁藥抽檢之選手, 以了解其比賽前 14 天使用營養增補劑的情形。營養增補劑種類包 括: 維生素/磺物質、胺基酸補給品、即時能量補給品、保健食品, 以及飲料類。本研究結果顯示 $88.1 \%$ 的運動員有使用營養增 補劑。不同種類的營養增補劑中, 選手使用率分別為維生素/礦物質 (48.1\%); 飲料 (45.9\%); 保健食品 (39.5\%); 胺基酸補給品 (31.9\%); 即時能量補給品 (24.9\%)。相較於男性選手，女性選手在維生素/磺物質 (55.0\% vs. 42.9\%) 與保健食品 (47.5\% vs. 33.3\%) 的使用率有較高的趨勢。在所有的運動項目中，舉重/健美以及游泳選手營養增補劑的使用率為 $100 \%$, 特別是舉重/健美選手對肌 酸 (69.7\%)，以及游泳選手對綜合維生素 $(76.2 \%)$ 有較高的使用率。此外，不同種類的營養增補劑中，選手最常使用的分別為維生 素/礦物質之綜合維生素 (37.3\%); 胺基酸補給品之肌酸 $(26.5 \%)$; 即時能量補給品之巧克力 (15.1\%); 保健食品類之動能食物膠囊 (16.2\%) ; 飲料類之運動飲料 $(42.4 \%)$ 。本研究對台灣優秀選手使用增補劑的現況之結果可作為教練、選手以及各級運動團體之參 考。

關鍵詞：全運會 運動 補給品

\section{Introduction}

Athletes, through years of vigorous training and continuous competitions, have undergone more physical and psychological stress compared to the general population. In order to maximize their performances, recover from vigorous training, compensate for inadequate diets, replenish nutrition, and avoid illnesses, athletes often use various nutritional supplements (Ciocca, 2005; Sobal \& Marquart, 1994a). Information from survey studies indicated that athletes have a higher tendency to use supplements as opposed to not using any, and that the use of supplements may vary with gender or sports (Calfee \& Fadale, 2006; DesJardins, 2002; Kristiansen, Levy-Milne, Barr, \& Flint, 2005; Nieper, 2005; Sobal \& Marquart, 1994b). These survey studies, however, were mainly conducted on college and high school athletes (Calfee et al., 2006; DesJardins et al., 2002; Kristiansen et al., 2005; Nieper et al., 2005; Sobal et al., 1994b;), and are scarce on information regarding national-class athletes (Baylis, Cameron-Smith, \& Burke, 2001; Huang, Johnson, \& Pipe, 2006; Slater, Tan, \& Teh, 2003). Therefore, it is essential to understand what supplements national-class athletes use and know the difference between Taiwan's athletes' supplement usage rates and that of other countries.
An open-ended questionnaire which surveyed Canada's elite athletes who participated at the 1996 Atlanta and 2000 Sydney Olympic Games revealed that the nutritional supplement usage rate was 69\% and 74\%, respectively (Huang et al., 2006), and that multivitamins were the most popular type of supplement. However, in Singapore, studies showed that among $77 \%$ elite athletes who used nutritional supplements, sports drinks were used most frequently (Slater, Tan, \& Teh, 2003), suggesting that a minor difference might exist between different countries.

In Taiwan, there has been no previous study targeting elite athletes' use of nutritional supplements. Since the athletes' use of nutritional supplements may be different from that of other countries, the objective of this study was to realize the prevalence and types of nutritional supplements used among Taiwan's elite athletes. In addition, factors such as gender and type of sport events are also considered in this study. 


\section{Materials and Methods}

\section{Subjects}

We chose the athletes sampled for doping control in the year 2007 of Taiwan National Athletic Games, the highest level of sports games in Taiwan. The subjects included gold and silver medalists, as well as record breakers. Data from a total of 185 athletes (105 males and 80 females) was collected. We divided the sports into 6 categories according to the competitive character: combat sports, weightlifting/bodybuilding, ball games, sprint/field events, swimming, medium and long-distance track event. Weightlifting and bodybuilding belong to the same category because they both emphasize on resistance training in training sessions. Sprint and field events are characterized by short term and intense-type activity for the most part, and thus are placed in the same category. Medium and long-distance track events both share continuous or endurance-type activity, and therefore are considered the same. Distribution of demographic characteristics for the athletes is listed in Table 1.

Table 1. Number of Athletes in Each Sport and Their Gender.

\begin{tabular}{llll}
\hline Sports & Number $(\%)$ & Gender & \\
\cline { 2 - 4 } Combat sports $^{\mathrm{a}}$ & $66(35.6)$ & 39 & Male \\
Weightlifting/bodybuilding & $33(17.8)$ & 22 & 27 \\
Sprint/Field events & $29(15.7)$ & 16 & 11 \\
Ball games & $27(14.6)$ & 14 & 13 \\
Swimming & $21(11.4)$ & 10 & 13 \\
Middle and long-distance track events & $9(4.9)$ & 4 & 5 \\
total & $185(100 \%)$ & 105 & 80 \\
\hline
\end{tabular}

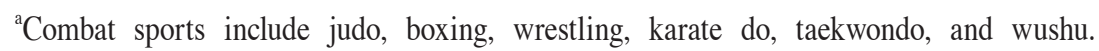

${ }^{\mathrm{b}}$ Ball games include basketball, baseball, tennis, table tennis, soft tennis and badminton.

\section{Procedure}

The study was performed at the Tainan stadium in Taiwan. We prepared an open-ended questionnaire for the athletes. As the athletes entered the doping control station waiting area, the interviewers explained the purpose of the investigation to the athletes while they were waiting and asked whether they would choose to be surveyed. After obtaining their consent, the interviewers proceeded to ask the athletes on their use of nutritional supplements within the last two weeks before the game. After having recorded the athletes' supplement usage, the interviewers requested that the athletes review the records and sign their names to verify there were no errors.

\section{Questionnaire}

The open-ended questionnaire design was developed based on "declaration of supplements: list supplements, including vitamins and minerals taken" in the doping control form. This questionnaire could help the athletes recall their usage of nutritional supplements. We sorted the nutritional supplements into five categories: vitamin/ mineral supplements, amino acid supplements (supplements that could assist muscle anabolism or enhance energy substrate availability), healthcare foods (food supplements that were considered to have a beneficial effect on human health), instant energy supplements (convenient supplements consumed prior to exercise that rapidly helped to energize bodies), and drinks (among which were sports drinks, functional drinks and effervescent drink tablets).

\section{Results and Discussions}

\section{Nutritional supplement use of Athletes}

Table 2 shows that $88.1 \%$ of the elite athletes participating at the 2007 Taiwan National Athletic Games used nutritional supplements. The average number of categories of nutritional supplements taken by the athletes was 2.1. The usage rate of Taiwan elite athletes was higher than that of Canadian elite athletes participating at the Atlanta and Sydney Olympic Games (69\% and 74\%, respectively) (Huang et al., 2006). It suggests that recently, Taiwan elite athletes' use of supplements is prevailing. 
The athletes' usage rates of vitamin/mineral supplements, amino acid supplements, healthcare foods, instant energy supplements, and drinks were 48.1\%, $31.9 \%, 39.5 \%, 24.9 \%$ and $45.9 \%$ respectively. Among the five categories of nutritional supplements, vitamin/mineral supplements were the most popular type of nutritional supplement. Our findings are similar to those of other nations (Baylis et al., 2001; Huang et al., 2006). Moreover, the usage rate of vitamin/mineral supplements is higher than that of the previous study on healthy adults in Taiwan (Chang \& Chiang, 2002), suggesting that more Taiwan elite athletes use vitamin/mineral supplements than healthy adults do. The benefits of vitamins/minerals for exercise can both serve as a cofactor to modulate energy metabolism and attenuate exercise-induced oxidative stress and muscle damage (Itoh et al., 2000). In contrast, several lines of evidence indicate that extra vitamin/mineral supplementation may fail to exert performance enhancing effects on athletes who consume balanced diets (Lukaski, 2004; van der Beek, 1991). Furthermore, vitamins/minerals may be deleterious to physical health once excessively ingested (Schrijver \& van den Berg, 2003).We found that the use of vitamin/mineral supplements is widespread among Taiwan's elite athletes, and some athletes use more than one type of vitamin/mineral supplements. Therefore, it is disputable whether repetitive intake of vitamins is appropriate.

\section{Gender Differences in the Use of Nutritional Supplements}

Table 2 shows the usage rates of nutritional supplements between male and female athletes were quite similar (87.6\% vs. 88.8\%). However, female athletes seemed to tend to use vitamin/mineral supplements $(55.0 \%$ vs. $42.9 \%)$ and healthcare foods $(47.5 \%$ vs. $33.3 \%)$ more. It has previously been reported that female athletes were more likely to take supplements for their health or because of an inadequate diet (Froiland, Koszewski, Hingst, \& Kopecky, 2004). Since vitamin/mineral supplements and healthcare foods share the common characteristic of promoting physical health, we deduced that this may be why female athletes consumed more on these categories of nutritional supplements than males did. However, the athletes' motives in consuming nutritional supplements remain uncertain and needs to be further explored.

Table 2. Nutritional Supplements Use by Taiwan Elite Athletes.

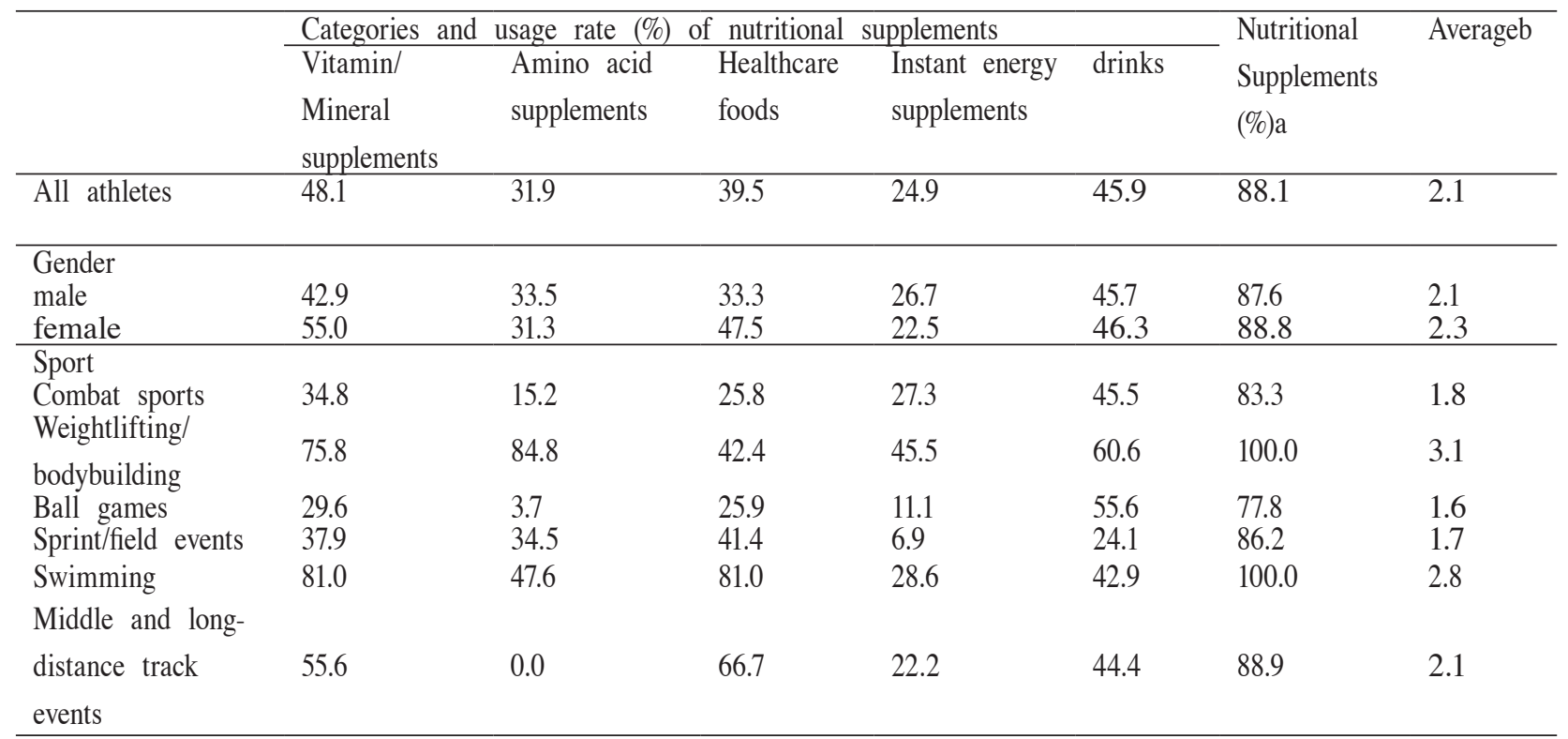

a Nutritional Supplement (\%) refers to the usage rate of overall use of any category of nutritional supplement by athletes.

$\mathrm{b}$ Average refers to average number of categories of nutritional supplements taken by athletes using them. 


\section{Use of Nutritional Supplements in Different Sports}

As shown in Table 2, among the six sport groups, all weightlifters/bodybuilders and swimmers had used the nutritional supplements (100\%). On average, weightlifters/ bodybuilders used 3.1 categories, while swimmers used 2.8 categories of the nutritional supplements. By nature of these sports, weightlifters/bodybuilders require heavy weight training regimens for the most part; on the other hand, a routine training for swimmers often involves either sprint for a few seconds, or a continuous, endurance-type activity that lasts for several hours. We assume that these athletes probably consumed more nutritional supplements to compensate for what was lost during training sessions. In contrast, ball game athletes' use of supplements was the lowest (77.8\%), with each athlete consuming only 1.6 categories of supplements on average. In addition, the three most used nutritional supplements vary with each sport. The highest prevalence of supplements for each sport was sports drinks for combat sports (28.8\%), ball games (45.5\%), and middle/long-distance track events (55.6\%), creatine for weightlifting/bodybuilding (69.7\%), multivitamins for swimming (76.2\%), and Cordymax Cs4 for sprint/field events (34.4\%) (Table 3). Besides, among all the supplements, multivitamin was the most used.

Creatine and multivitamins were most commonly used by weightlifters/bodybuilders and swimmers, respectively. One possible reason is that weightlifters/bodybuilders use creatine to construct the muscle, while swimmers use multivitamins to modulate energy metabolism. In contrast, data indicates that ball game athletes rarely used nutritional supplements. This finding is similar to that of the Canadian elite athletes on the use of supplements across the spectrum of sports (Huang et al, 2006). In this study, besides supplementation of drinks, the usage rate of other categories of nutritional supplements by ball game athletes was also the lowest. By the characteristics of the sport competitions, we found that ball games are mostly team sports, but all other sports are individual competitions. Previous studies considered that team sports athletes may receive more support from their colleagues and have greater confidence in their capabilities; thus their use of supplements is less. On the other hand, the athletes in the individual games tend to use supplements to increase their confidence (Huang et al, 2006).

It should be noted that creatine use in some sports appears to contradict the often-quoted concept in sports science. Creatine could enhance ATP-PC system that benefits short-term, high intensity exercise. Hence, creatine use is suitable for strength and power athletes, such as weightlifters/bodybuilders and sprint/field athletes. However, if weightlifters/bodybuilders are excluded from the study, the usage rate of creatine was most prevalent in swimmers, and the usage rate was higher than that of sprint/field athletes by $18 \%$. Moreover, it is also higher than the findings that surveyed Australian swimmers' use of creatine (Baylis et al., 2001). (47.6\% vs. 31\%). From the perspective of the source of energy supply during exercise, swimming relies more on the lactic acid system and the aerobic system to energize the body than on the ATPCP system. Thus, unlike sprint/field athletes, swimmers need less creatine. Although evidence indicates that creatine may provide ergogenic potential on swimmers' performances (Grindstaff et al., 1997), most studies fail to support this statement (Dawson, Vladich, \& Blanksby, 2002; Mendes, et al., 2004; Silva et al., 2007). Therefore, whether Taiwanese elite athletes' usage of creatine is due to their ambitions to win the championship or simply out of incorrect concepts should be further studied.

Table 3. The Top 3 Popular Nutritional Supplements Use by Taiwan Elite Athletes in Different Sports.

\begin{tabular}{llll}
\hline & Supplement and \% use & & \\
\cline { 2 - 4 } Sport 1 & Top 2 & Top 3 \\
Combat Sports & Sports drink (28.8) & Multivitamin (27.3) & Chocolate (21.2) \\
Weightlifting/bodybuilding & Creatine (69.7) & Whey protein (57.6) & Multivitamin (51.5) \\
Sprint/Field events & Cordymax Cs-4 (34.4) & Multivitamin (27.5) & Creatine (24.1) \\
Ball games & Sports drink (45.5) & Multivitamin (18.5) & Vitamin B (11.1) \\
Swimming & Multivitamin (76.2) & Cordymax Cs-4 (47.6) & Creatine (47.6) \\
$\begin{array}{l}\text { Middle and long-distance } \\
\text { track events }\end{array}$ & Sports drink (55.6) & Cordymax Cs-4 (55.6) & Multivitamin (44.4) \\
\hline
\end{tabular}




\section{The Most Popular Supplement in Different Category}

As shown in Figure 1, Taiwan elite athletes used 8 types of vitamin/mineral supplements. Among them, multivitamins were the most popular type (37.3\%); There were 6 types of amino acid supplements used by athletes in this study (Figure 2). The most popular amino acid supplement was creatine, with a usage rate of $26.5 \%$; Athletes consumed 4 types of instant energy supplements. Among those supplements, the usage rate from the highest to the lowest was chocolate (15.1\%), energy jell (8.6\%), energy bar (4.3\%) and glucose (2.2\%); Athletes used 18 types of healthcare foods (Figure 3), among them, Cordymax Cs-4 was the most popular (16.2\%); The usage rate of drinks was $42.2 \%$ for sports drinks, $11.4 \%$ for functional drinks, and $1.1 \%$ for effervescent drink tablets.

Multivitamins, followed by sports drinks, were the two most popular supplements used by Taiwan elite athletes. This finding closely resembles the surveys on Canadian elite athletes at the Atlanta and Sidney Olympic Games (Huang et al., 2006), and those on Singaporean elite athletes as well (Slater et al., 2003). The most popular supplement used by the Canadian elite athletes is multivitamins. Singapore's elite athletes, however, use sports drinks the most (Slater et al., 2003). Therefore, despite the minor difference on usage with different countries, Taiwan elite athletes' current use of supplements is similar to the type of supplements frequently used by elite athletes around the world.

Creatine is the most popular amino acid supplement used by Taiwain elite athletes. Ever since Harris, Soderund and Hultman (1992) declared the relationship between creatine and sports, growing studies have been established on the roles of creatine in sports performances over the last decade. Athletes' use of creatine to enhance strength and power capacity is widespread. The current survey shows that weightlifting/bodybuilding and sprint/ fields events demand creatine the most, since creatine enhances the performance of explosive strength.

As for healthcare foods, Overdrive Capsule and CordyMax Cs-4 are most commonly used (Figure 3). These supplements claim to have anti-fatigue effect, and are labeled with "Designated products of the Chinese Taipei Olympic Committee". Additionally, they were provided by manufacturers for free.
This study found that athletes tend to use portable instant energy supplements prior to competitions. Among these supplements, chocolate was more popular than power bars and power jellies. A more probable explanation for this is that chocolate is cheaper.

Among the use of drinks, sports drinks were the most commonly used. The usage rate of sports drinks in Taiwan elite athletes is much higher than that of Canadian elite athletes (42.4\% vs. 22.4\%) (Erdman, Fung, Doyle-Baker, Verhoef, \& Reimer, 2007).. Since Taiwan is in the subtropical zone, which is hot and humid, Taiwan athletes are likely to feel thirsty during training. Elite athletes from Singapore, having faced a similar climate pattern, had a resemblance in usage rates of sports drinks in comparison to Taiwan elite athletes (Baylis et al., 2001) $(39.0 \%$ vs. $42.4 \%)$. Therefore, geographic factors may also influence elite athletes' use of supplements.

\section{Study Limitations}

Limitations common to this study should be noted. First, the data were based on national class athletes. The generalization of the present finding to the athletes who are not national class athletes may be limited. The second is that we did not investigate the motivation for athletes' supplement use, which may limit our interpretations. In spite of these minor shortcomings, this research has provided valuable information on the current usage of nutritional supplementation in Taiwan elite athletes.

\section{Conclusion}

The use of supplements was widespread among Taiwan elite athletes. The most consumed types in nutritional supplements were: multivitamins for vitamin/ mineral supplements, creatine for amino acid supplements, chocolate for instant energy supplements, Cordymax Cs-4 for healthcare foods, and sports drinks for drinks. Female athletes had a higher tendency to use vitamin/mineral supplements $(55.0 \%$ vs. $42.9 \%)$ and healthcare foods (47.5\% vs. $33.3 \%)$ than male athletes did. In addition, weightlifters/bodybuilders and swimmers seemed to use nutritional supplements the most (100\%), particularly amino acid supplements and vitamin/mineral supplements. 
In the present study, athletes appear to choose supplements more carefully. However, it seems that some athletes might have simply followed the trend of supplement use. Also, the reasons of use are still disputable, as well as the kinds and dosage of supplements. In conclusion, the results of this study could be served as a reference for future studies on sports nutrition for Taiwan elite athletes.

Figure 1. Types and usage rate of vitamin/mineral supplements used by athletes.

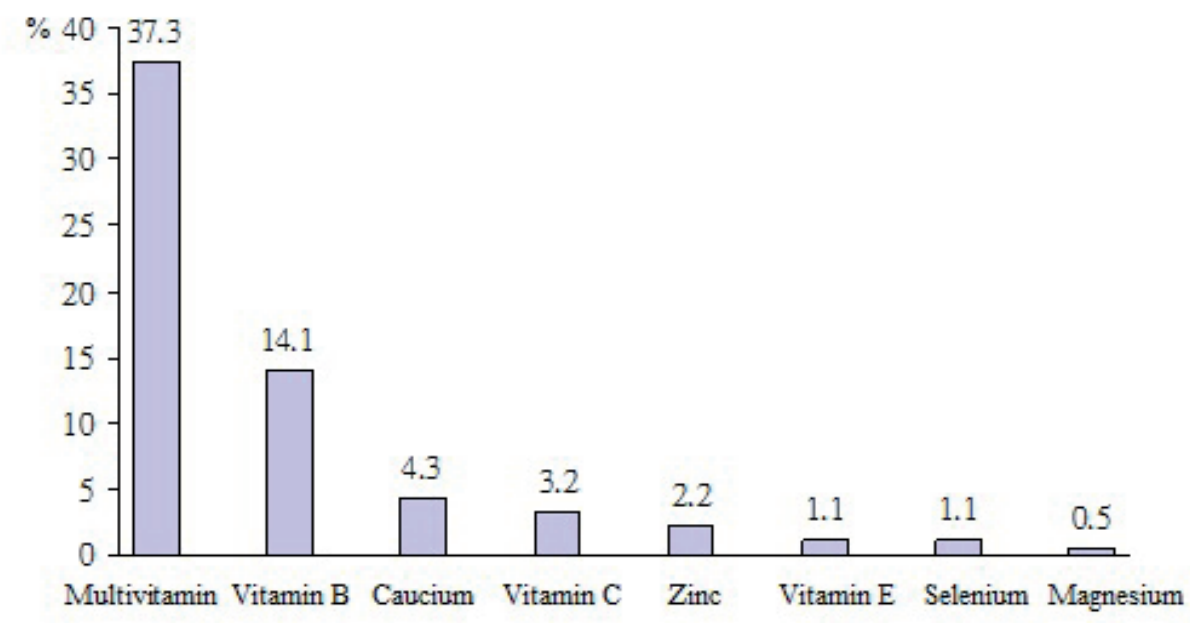

Figure 2. Types and usage rate of amino acid supplements used by athletes.

HMB: beta-hydroxy beta-methylbutyrate. BCAA: branch chain amino acids.

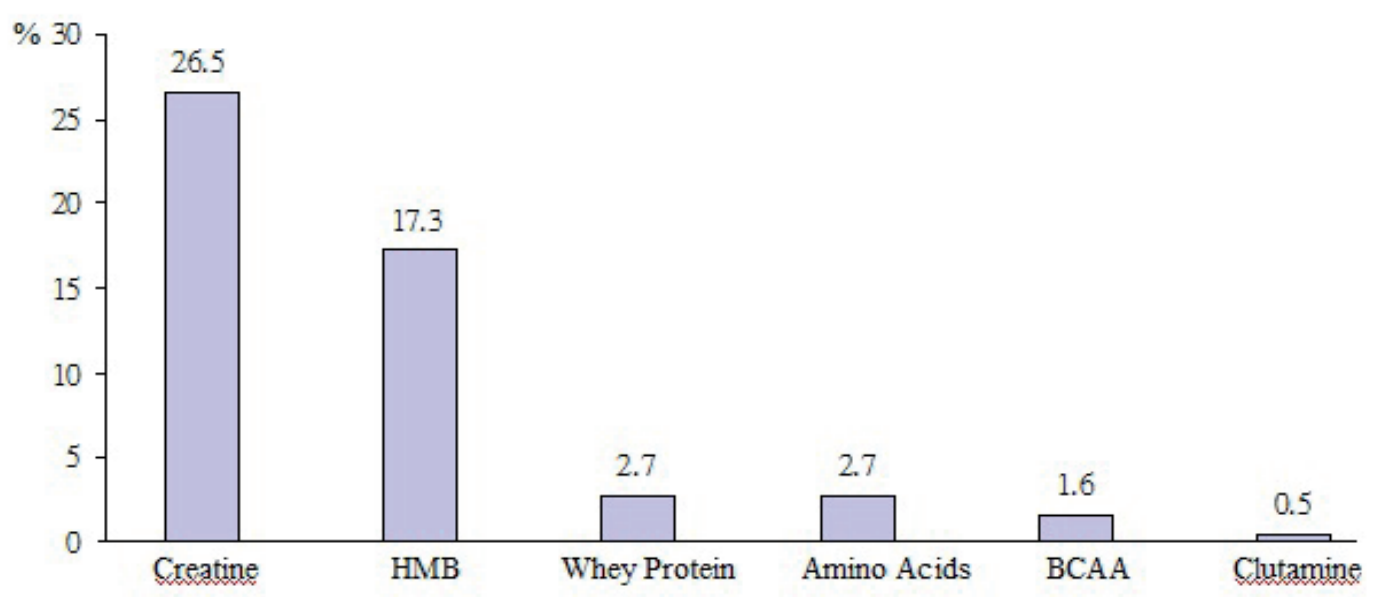


Figure 3. Types and usage rate of health foods used by athletes. OverDrive: a supplement that claimed to help individuals in trying to achieve their fitness goals, overcome the barriers of fatigue, and slow recovery rate. Abbott Ensure: A supplement powder dissolved with water for administration, which contains various nutritents. Silymarin Plus Tablets: a supplement in tablet form which mainly contains Silybum Marianum, inostiol, Vitamin $\mathrm{E}$ and Vitamin $\mathrm{C}$ to support healthy liver function.

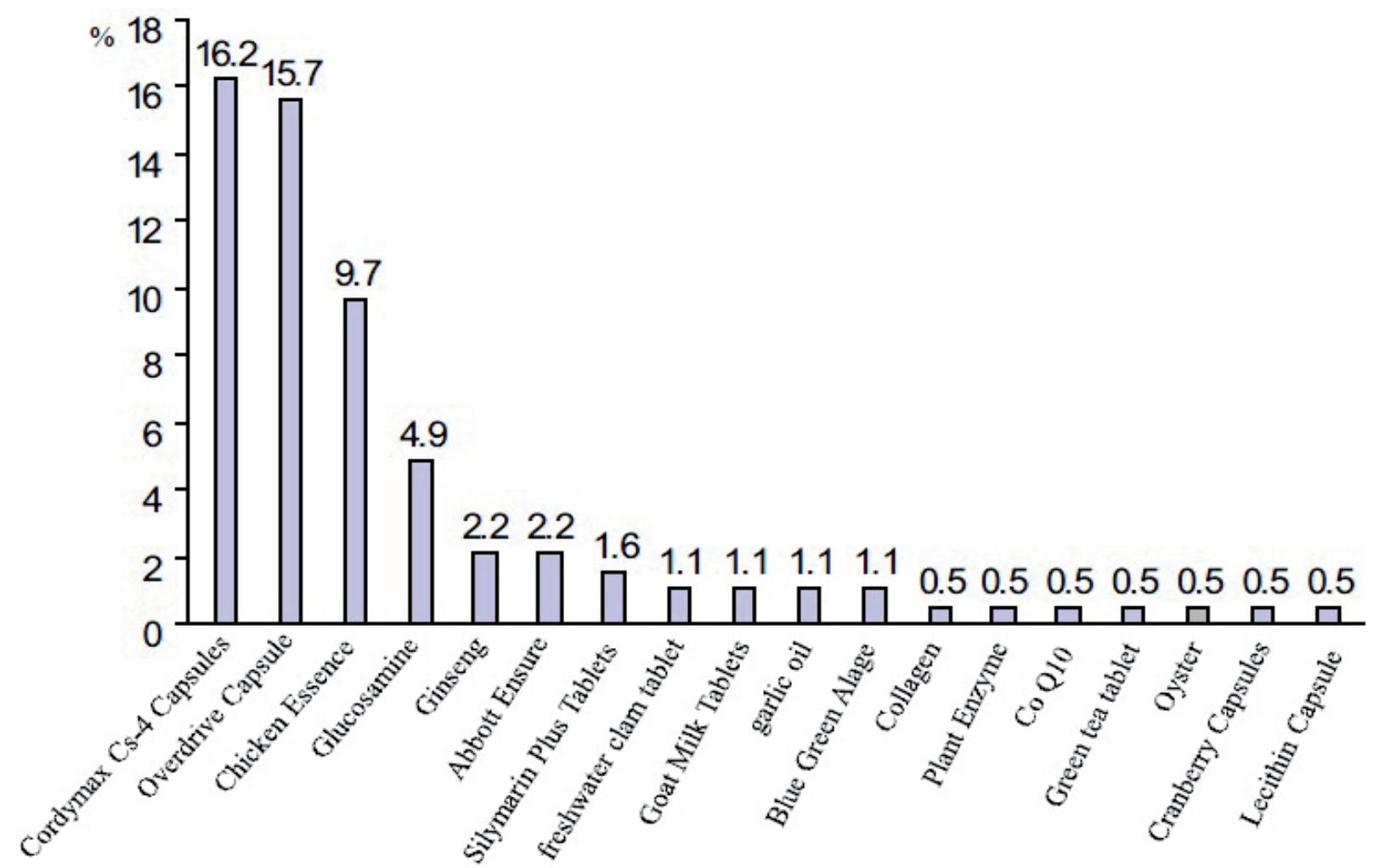

\section{References}

Baylis, A., Cameron-Smith, D., \& Burke, L. M. (2001). Inadvertent doping through supplement use by athletes: assessment and management of the risk in Australia. International Journal of Sport Nutrition and Exercise Metabolism, 11(3), 365-383.

Calfee, R., \& Fadale, P. (2006). Popular ergogenic drugs and supplements in young athletes. Pediatrics, 117(3), e577-589.

Chang, C. H., \& Chiang, T. L. (2002). Vitamin/calcium supplement use in Taiwan: findings from the 1994 National Health Interview Survey. Kaohsiung Journal of Medical Sciences, 18(4), 171-181.

Ciocca, M. (2005). Medication and supplement use by athletes. Clinics in Sports Medicine, 24(3), 719-738.
Dawson, B., Vladich, T., \& Blanksby, B. A. (2002). Effects of 4 weeks of creatine supplementation in junior swimmers on freestyle sprint and swim bench performance. Journal of Strength \& Conditioning Research, 16(4), 485-490.

DesJardins, M. (2002). Supplement use in the adolescent athlete. Current Sports Medicine Reports, 1(6), 369373.

Erdman, K. A., Fung, T. S., Doyle-Baker, P. K., Verhoef M. J., \& Reimer, R. A. (2007). Dietary supplementation of high-performance Canadian athletes by age and gender. Clinical Journal of Sport Medicine, 17(6), 458-464.

Froiland, K., Koszewski, W., Hingst, J., \& Kopecky, L. (2004). Nutritional supplement use among college athletes and their sources of information. International Journal of Sport Nutrition and Exercise Metabolism, 14(1), 104120. 
Grindstaff, P. D., Kreider, R., Bishop, R., Wilson, M., Wood, L., \& Alexander, C. et al. (1997). Effects of creatine supplementation on repetitive sprint performance and body composition in competitive swimmers. International Journal of Sport Nutrition, 7(4), 330-446.

Harris, R. C., Soderund, K., \& Hultman, E. (1992). Elevation of creatine in resting and exercise muscle of muscle of normal subject by creatine supplementation. Clinical Science, 83(3), 367-374.

Huang, S. H., Johnson, K., \& Pipe, A. L. (2006). The use of dietary supplements and medications by Canadian athletes at the Atlanta and Sydney Olympic Games. Clinical Journal of Sports Medicine, 16(1), 27-33.

Itoh, H., Ohkuwa, T., Yamazaki, Y., Shimoda, T., Wakayama, A., \& Tamura, S. et al. (2000). Vitamin E supplementation attenuates leakage of enzymes following 6 successive days of running training. Internal National Journal of Sports Medicine, 21(5), 369-374.

Kristiansen, M., Levy-Milne, R., \& Barr, S. \& Flint, A. (2005). Dietary supplement use by varsity athletes at a Canadian university. International Journal of Sport Nutrition and Exercise Metabolism, 15(2), 195-210.

Lukaski, H. C. (2004). Vitamin and mineral status: effects on physical performance. Nutrition, 20(7-8), 632-644.

Mendes, R. R., Pires, I., \& Oliveira, A, et al. (2004). Effects of creatine supplementation on the performance and body composition of competitive swimmers. The Journal of Nutritional Biochemistry, 15(8), 473-478.

Nieper, A. (2005). Nutritional supplement practices in UK junior national track and field athletes. British Journal of Sports Medicine, 39(9), 645-649.

Schrijver, J., \& van den Berg, H. (2003). [Nutrition and health--vitamins and vitamin supplements]. Nederlands Tijdschrift Voor Geneeskunde, 147(16), 752-756.
Silva, A. J., Machado, Reis, V., Guidetti, L., Bessone, Alves. F., Mota, P., \& Freitas, J. et al. (2007). Effect of creatine on swimming velocity, body composition and hydrodynamic variables. Journal of Sports Medicine and Physical Fitness, 47(1), 58-64.

Slater, G., Tan, B., \& Teh, K. C. (2003). Dietary supplementation practices of Singaporean athletes. International Journal of Sport Nutrition and Exercise Metabolism,13(3), 320-322.

Sobal, J., \& Marquart, L. F. (1994a). Vitamin/ mineral supplement use among high school athletes. Adolescence, 29(116), 835-843.

Sobal, J., \& Marquart, L. F. (1994b). Vitamin/mineral supplement use among athletes: a review of the literature. International Journal of Sport Nutrition, 4(4), 320-334.

van der Beek, E. J. (1991). Vitamin supplementation and physical exercise performance. Journal of Sports Science, 9, 77-90.

\section{Acknowledgements}

We greatly appreciate the Chinese Taipei Olympic Committee for assist this study.

\section{Correspondence}

\section{Mei-Chich HSU}

Address: Graduate Institute of Sports Science, National Sports University, Taoyuan County, Taiwan. 250 Wenhua 1st Rd., Gueishan, Taoyuan County, Taiwan 333, R.O.C

Phone : +886-3-328-3201, ext 2421

Fax : + $+886-3-331-1843$

Email : meichich@gmail.com 